\title{
The Reasons, Determinants, and Effect of Private Tutoring in the Greater Chinese Regions
}

\author{
Qin Xiang ${ }^{1, \mathrm{a}}$ \\ ${ }^{1}$ Shanghai Normal University Tianhua College \\ ${ }^{a}$ Email:939606613@qq.com

\begin{abstract}
As an educational phenomenon, private tutoring has developed for decades and has a vast amount of demand in four Chinese regions, mainland China, Hongkong, Taiwan, and Macao. The article attempted found the reasons, factors related with the participation and the effectiveness of private tutoring in these regions by analysing the data in the previous studies. Private tutoring resulted in the unequal opportunity for the children from different family background. The study is significant for formulation and implement of the policies in education field.
\end{abstract}

Keywords: Private tutoring, Shadow education, Reasons, Effectiveness.

\section{INTRODUCTION}

The paper focuses on the empirical studies of private tutoring in greater Chinese regions. The following research questions will guide the review: (a) what are the reasons for the vast demands of private tutoring in these regions? (b) what factors are related with students' participation in private tutoring? (c) what is the influence of private tutoring on students?

\subsection{Definition of private tutoring}

Private tutoring was described as shadow education during the 1990s. It mainly referred to the outside schooling activities to enhance students' formal school performance, which coexists and changes with the formal school system and curriculum, and mimics of the formal school system just like a shadow ${ }^{[1][2] \text {. }}$

Bray and Zhan articulated three specific components of private tutoring activity ${ }^{[3]}$. First, private tutoring institutions or companies is commercial and profitbased. Private tutoring is provided in a purpose of exchange for pay, excluding the extra tutoring provided by teachers, friends, and family members free of charge. Second, it is mainly concerned with languages (Chinese and English), mathematics, and other examination subjects in the formal schooling system. The purpose of the tutoring is to raise the student's examination scores. The third, it focuses on tutoring in after school time excluding instruction during the regular school day.

\subsection{Backgrounds of private tutoring in greater Chinese regions}

Private tutoring has gained particular attention in recent decades in the greater Chinese regions. In mainland China, Zhang \& Bray ${ }^{[4]}$ surveyed a total sample of 1680 students in eight primary schools and eight lower secondary schools. The research indicated that $58.7 \%$ of sampled students in Grades 3-9 had received private tutoring from 2016 to 2017. Mathematics and English were the two most popular subjects. About $81.5 \%$ and $76.8 \%$ of students received private tutoring in the two subjects. In Taiwan, a study showed 789 out of the 1,698 teenage English learners in public secondary schools (46\%) reported the additional private tutoring of English with an average of 4 hours or above of instruction time per week ${ }^{[5]}$. In Hong Kong, Lee $^{[6]}$ found that $34 \%$ of junior secondary and $40 \%$ of senior secondary students received private tutoring in 1996. Bray \& Kobakhidze ${ }^{[7]}$ indicated that $53.8 \%$ in grade 9 and $71.8 \%$ in grade 12 among the sampled students received private tutoring in 2015. The percentage increased considerably in the late 20 years. In Macao, $\operatorname{Vong}^{[8]}$ reported that around $70 \%$ of kindergarten and primary school students received private tutoring in 2011. The statistical data above shows the general situation and trend of private tutoring in greater Chinese regions. 


\section{REASONS FOR THE PARTICIPATION OF PRIVATE TUTORING}

The reasons were analysed from the aspects of society, school, and family.

\subsection{Society}

First, the Confucian culture was believed to be one of the reasons why the private tutoring prospered in the Chinese communities ${ }^{[9]}$. Bray \& Lykins ${ }^{[10]}$ indicated that Confucian philosophy emphasized education and diligence. Extra learning activities were parts of the culture. Guided by Confucian culture, they took extra tutoring as an essential part of their life. Chinese parents were willing to invest in education ${ }^{[11]}$.

Second, the marketization of the tutoring system afforded plenty of choices to meet families demand for private tutoring. A massive amount of advertisement was found on television, the Internet, or through flyers to persuade families to take part in private tutoring classes $^{[12]}$. The private tutoring institutions emphasized their ability to improve the scores in examination as part of their marketing strategy ${ }^{[13]}$.

The third was the hierarchy of the society. Most parents hoped their children could get a high social status. Students and parents took educational qualifications as the ladders to climb higher in the hierarchy society ${ }^{[9]}$. One should get a high quality education if he wanted to access a better-paying decent job. So winning in examinations and being enrolled in a high-level university were taken as the destination of education by most parents and even teachers ${ }^{[14]}$. A limited number of students have the chance to colleges. In this context, parents and students thought it was not adequate for them to learn only in schools. Many of them were willing to invest in extra private tutoring to help students gain a competitive edge in the race for university places and then the higher positions in the job market $^{[15]}$

\subsection{School and family}

The school systems in the greater Chinese regions were examination oriented. Except for the external entrance examinations that grade six (Students in mainland China ) and grade 12 students should take, most of the schools also had many internal examinations $^{[7]}$. Zhan, Bray, et al. ${ }^{[16]}$ had a survey on the reasons for taking tutoring among secondary students. The result showed that $76.3 \%$ of Grade 9 students had the choice 'to improve examination scores' and this number jumped to $92.1 \%$ for those of Grade 12. A survey of 983 Grade 11 students in eight schools in Hongkong found that $36.5 \%$ felt anxious in the examinations and sought help from private tutoring ${ }^{[17]}$. For many students, private tutoring has become an important channel to relieve their pressure in examination $^{[16]}$

Absence of the parents was part of the reasons for the students to seek help from private tutoring when they were in trouble in their study. More parents worked longer hours, especially in large cities. They did not have enough time to help with the assignment from school. Bray \& Kobakhidze $^{[7]}$ had a survey to the secondary students. Most of them said that they met their parents only during dinner time or at weekends. Only a few students mentioned that parents could assist with their homework. Some reported that parents only checked whether homework had been finished or not. While some parents did not even do that. Other students mentioned that their parents wanted to give some assistance, but they were lack of knowledge in that particular subject. So many families seek help from the private tutoring institutions.

\section{FACTORS RELATED WITH THE PARTICIPATION RATE OF PRIVATE TUROTING}

In the expansion of private tutoring, a growing literature examined the factors which decided the participation rate of private tutoring. In the review, the following factors were included: family social economic status, quality of the school, grade, gender, parental education, and residential area.

\subsection{Family social and economic status}

The Family economic status showed a general significant influence on the participation of private tutoring. In the research of Bray et al. ${ }^{[3]}$, it was reported that with family monthly income increased by 1.0 , the monthly expenditure in private tutoring increased by 0.067. Family income significantly influenced students' private tutoring expenditures. Zhou \& $\mathrm{Wang}^{[9]}$ had a survey on the influence of family background on the likelihood of having private tutoring classes in Hongkong, Taiwan, Shanghai, and Macao. They concluded that family social and economic status was positively associated with the probability of private tutoring participation in all the four regions. The positive correlation was consistent with the result from the studies by Malik \& Liu ${ }^{[11]}$, Zhang \& Bray ${ }^{[19]}$, and Zhang \& Xie ${ }^{[18]}$. They indicated that families with private cars and higher incomes were more likely to invest in tutoring. Students got less chances to private tutoring due to unfavourable conditions.

Some research showed higher parental education predicted their children's higher likelihood of private tutoring attendance. Parents with higher educational level were more willing to invest in children's education and private tutoring ${ }^{[18][19]}$. However, in the research of Bray et al., ${ }^{[3]}$ and Zhang and Bray ${ }^{[19]}$, they indicated that 
mother's and father's education level had no significant influence on the likelihood of private tutoring. The authors gave the interpretation that access to tutoring was determined more by parental economic capital than by parental cultural capital. The interviews with the parents supported the idea. It suggested that parents would like to invest in the extra classes for their children as long as they could afford them.

\subsection{Residential area}

The residential area of the students were found to have a significant relationship with the participation rate of private tutoring. In the research by Bray et al. ${ }^{[3]}$, it showed that students with Shanghai hukou (household registration) and those in the urban districts generally had more chances to private tutoring. Liu \& Bray ${ }^{[19]}$ and Zhang \& Bray ${ }^{[19]}$ gave the similar decision that students in suburban areas had less chances to receive tutoring than their urban counterparts. In some studies, the classification of urban/rural differences may be defined by hukou as well as place of residence. Concerning residence, significant differences were found in probability for private tutoring among students with or without hukou in one region ${ }^{[20]}$. The authors explained the phenomenon from several aspects. Students in urban areas were facing the fiercer competition among the peers. Tutoring institutions were likely to concentrate in the urban area with higher population densities and stronger demand capacity. Comparatively rural families might get less competition and pressure from their communities and schools to seek tutoring ${ }^{[19]}$.

\subsection{Quality of the school}

Most people commonly assumed that lower achievers or students from low-quality schools were more apt to receive private tutoring. However, some literatures provided the opposite result. Bray, et al. ${ }^{[3]}$ surveyed 1624 students in Grades nine and 12 from 16 secondary schools in Hongkong. The study indicated that the level of the school had significant relationships with the probability of receiving private tutoring. The results showed $74.2 \%$ of students in Level One schools (with the highest achievers) received tutoring, compared with $61.7 \%$ of students in Level Two schools (with the middle achievers) and $48.6 \%$ of students in Level Three (with the lowest achievers) schools. As noted above, Students in higher achievement schools were more likely to receive tutoring than those in lower achievement schools. Another research in Shanghai reported that higher academic level students were more likely to receive tutoring. It resemble the experience in Japan and South Korea with positive relationship between school quality and demand for private tutoring ${ }^{[19]}$.

\subsection{Grade and Gender}

The In the research of Bray et al. ${ }^{[3]}$, the authors found that grade was a significant factor to decide private tutoring with the fact that $71.8 \%$ of Grade 12 students took part in tutoring compared with $53.8 \%$ of Grade 9 students. It might connect to the condition that Grade 12 students were about to take part in the entrance examination which was significant to their lives in the future.

In traditional way of thinking, families tended to invest more in males' education. The literatures concluded that gender had no significant relationship with the probability of receiving private tutoring. In Zhang's study ${ }^{[20]}$ in Jinan, mainland of China, larger proportions of females were found receiving tutoring in English and Chinese, no significant difference in mathematics. Bray et al. ${ }^{[3]}$ also indicated that $65.6 \%$ of females in the sample received tutoring compared with only $56.8 \%$ of males. In the case in Beijing, it reported that $56 \%$ amongst the girls received private education to $48 \%$ amongst the boys. It appeared that private education was slightly more common among the girls than among the boys ${ }^{[11]}$. This thesis was supported by other research ${ }^{[19][21]}$. There was no significant difference between males and females in the probability of receiving tutoring in mainland China. However, research in other countries reported that boys usually got the priority for family investments in education if the educational resources were not enough for all children in one family ${ }^{[21]}$. The inconsistency might related with the areas having different economic development levels.

\section{EFFECTIVENESS OF PRIVATE TUTORING}

Parents care about most if private tutoring can improve the academic achievement in the standardized examinations in school. Private tutoring has other effects, such as the influence on students' psychology and learning motivation ${ }^{[21]}$. Both positive and negative effect were found in the previous studies on the three aspects.

\subsection{Positive effects}

Zhang \& $\mathrm{Xie}^{[22]}$ found that increased spending on tutoring was an significant factor to improve students' math performance. Children's academic ability could correlate with their private tutoring experiences. The similar results were reported based on the survey from 10,513 senior secondary students in three provinces and one municipality by Lei ${ }^{[23]}$.

Yung $^{[24]}$ interviewed 14 Chinese learners with English private tutoring during their secondary education in Hong Kong. They thought that it was 
effective in helping them prepare for the English examinations. The idea was proved by $\mathrm{Tse}^{[15]}$. Over 75.5 $\%$ of the children receiving tutoring thought that they had improved their Chinese competence in the private tutoring classes.

Bray and $\mathrm{Ora}^{[25]}$ indicated that private tutoring were helpful in a psychological way. For the slow learners, private tutoring could help to keep up with their peers, which supported children's self-esteem and sense of achievement. For the parents, tutoring reassured themselves that they had assisted their children at crucial stages. Tutoring also played a role in learners' self-related motivation. Huang ${ }^{[26]}$ found that students with additional tutoring had a stronger intention to learn English. At the same time, they exhibited a higher frequency to English learning both in and out of school compared with those who only took English classes in schools. Zhan etc. ${ }^{[24]}$ used a quantitative survey to identify students attitude to different types of tutoring. It was found that students considered one-on-one tutoring to be effective in improving their examination grades and learning strategies, lecture-type tutoring to be effective in improving their confidence in examinations, revision skills and learning strategies.

\subsection{Negative effect}

Some studies showed that private tutoring played a relatively unimportant or even a negative role. For example, Lin and Chen ${ }^{[27]}$ concluded that 'cramming' via private tutoring did not necessarily improve Taiwan students' scores in college entrance examinations. Chiang ${ }^{[28]}$ found that the negative impact of intensive tutoring on learning attainment especially when students spent many hours receiving tuition in practicing responses and memorizing answers to the test questions.

Private tutoring put pressure on the families in both economic and psychological aspects. A survey in Hongkong by Bray and Ora ${ }^{[25]}$ indicated that over one third of sampled families alleged that costs in private tutoring were a burden to them. For some families, these costs per child took up between $20.3 \%$ and $30.5 \%$ of estimated households incomes. For the students, much of time was taken by extra lessons. They had less time for sports, shopping, and friends. Some psychological warnings was sent to the students because the intensity of the tutoring.

\section{CONCLUSION}

Based on the review above, the article drew the following conclusions:

\subsection{Reasons for private tutoring were complicated}

Reasons for the vast demand of private tutoring came from parents, school, tutoring institutions, and society. For the parents and the students, they were more concern about winning in school and being enrolled in an elite college ${ }^{[29]}$. They sought to the extra tutoring to gain priority in competing with their peers. The commercial institutions just could meet the demand of these families.

\subsection{The mixed influence of tutoring}

There are both positive and negative influence of private tutoring on students' learning activities. Private tutoring could help students in a psychological way, such as self-esteem, sense of achievement, and stronger self-motivation to learn. Most families took part in private tutoring with the purpose of improving the academic performance. The negative effect of private tutoring was also distinct on the aspects of economic burden to the families, psychological influence on students and occupation of their spare time.

\subsection{The unequal opportunities in educational attainment}

The two factors influencing the probability of taking part in private tutoring came from family economic status and residential area. The students got more opportunity to private tutoring if they had a higher family income or lived in the urban area. Some students from poverty families of rural area could not afford the tutoring. In a sense, private tutoring played a role for the unequal attainment in educational opportunity.

\section{REFERENCES}

[1] Bray T. M. , The shadow education system: Private tutoring and its implications for planners. UNESCO International Institute for Educational Planning., 1999.

[2] Stevenson D. L. \& Baker D. P., "Shadow education and allocation in formal schooling: Transition to university in Japan". American journal of sociology, 97(6), 1992, pp. 1639-1657.

[3] Bray, M., Zhan, S. , Lykins, C., Wang, D. \& Kwo, O. "Differentiated demand for private supplementary tutoring: Patterns and implications in Hong Kong secondary education". Economics of Education Review, 38, 2014, pp. 24-37.

[4] Zhang, W., \& Bray, M. , "Equalising schooling, unequalising private supplementary tutoring: access and tracking through shadow education in 
China". Oxford Review of Education, 44(2), 2018, pp. 221-238.

[5] Huang, H. T., "Private English tutoring and adolescents' motivation to learn English as a foreign language: a self-system perspective". Taiwan Journal of TESOL, 14(1), 2017, pp. 1-36.

[6] Lee, C., Children and private tuition. Youth poll series, 34, 1996.

[7] Bray, M., \& Kobakhidze, M. N., "Evolving ecosystems in education: The nature and implications of private supplementary tutoring in Hong Kong”. PROSPECTS, 45(4), 2015, pp. 465481 .

[8] Vong, S. K.. "Discussion on the issue of private tutoring problems in Macao". Part I. Macao Daily, 2011, April 4.

[9] Zhou, Yisu, and Dan Wang. "The family socioeconomic effect on extra lessons in Greater China: A comparison between Shanghai, Taiwan, Hong Kong, and Macao." The Asia-Pacific Education Researcher 24.2 (2015): 363-377.

[10] Bray, Mark, and Chad Lykins. Shadow education: Private supplementary tutoring and its implications for policy makers in Asia. No. 9. Asian Development Bank, 2012.

[11] Malik, Muhammad Abid, and Baocun Liu. "Shadow education in Beijing: Determinants and disparities from the perspectives of the students." International Journal of Research Studies in Education 7.2 (2018): 53-65.

[12] Wang, Dan, and Mark Bray. "When whole-person development encounters social stratification: Teachers' ambivalent attitudes towards private supplementary tutoring in Hong Kong." The AsiaPacific Education Researcher 25.5 (2016): 873881.

[13] Bray, Mark, and Magda Nutsa Kobakhidze. "Evolving ecosystems in education: The nature and implications of private supplementary tutoring in Hong Kong." Prospects 45.4 (2015): 465-481.

[14] Luk, H. K. B. "From under banyan trees to in front of computers: Stories of education in Hong Kong." Hong Kong: Step Forward Multi Media Co.[in Chinese] (2003).

[15] Tse, Shek Kam. "To what extent does Hong Kong primary school students' Chinese reading comprehension benefit from after-school private tuition?." Asia Pacific Education Review15.2 (2014): 283-297.
[16] Zhan, Shengli, et al. "The effectiveness of private tutoring: Students' perceptions in comparison with mainstream schooling in Hong Kong." Asia Pacific Education Review 14.4 (2013): 495-509.

[17] Ho, S., Early exam jitters over new subject. The Standard, 28 March, 2011.

[18] Zhang, Yueyun, and Yu Xie. "Family background, private tutoring, and children's educational performance in contemporary China." Chinese sociological review 48.1 (2016): 64-82.

[19] Liu, Junyan, and Mark Bray. "Determinants of demand for private supplementary tutoring in China: Findings from a national survey." Education Economics 25.2 (2017): 205-218.

[20] Zhang, Yu. "Does private tutoring improve students' National College Entrance Exam performance?-A case study from Jinan, China." Economics of Education Review 32 (2013): 1-28.

[21] Aslam, M., and P. Atherton. "The shadow education sector in India and Pakistan: The determinants, benefits and equity effects of private tutoring (Mimeo)." London, UK: Institute of Education, University of London (2013).

[22] Zhang, Yueyun, and Yu Xie. "Family background, private tutoring, and children's educational performance in contemporary China." Chinese sociological review 48.1 (2016): 64-82.

[23] Lei, Wan-peng. "Expenditures of private supplementary tutoring by high school students: Influential factors and policy implications." Education and Economics 1 (2005): 39-42.

[24] Yung, Kevin Wai - Ho. "Learning English in the shadows: Understanding Chinese learners' experiences of private tutoring." Tesol Quarterly 49.4 (2015): 707-732.

[25] Bray, Mark, and Ora Kwo. "Behind the façade of fee-free education: Shadow education and its implications for social justice." Oxford Review of Education 39.4 (2013): 480-497.

[26] Huang, Hung-Tzu. "Private English Tutoring and Adolescents' Motivation to Learn English as a Foreign Language: A Self System Perspective." Taiwan Journal of TESOL 14.1 (2017): 1-36.

[27] Lin, Da-Sen, and Yi-Fen Chen. "Cram school attendance and college entrance exam scores of senior high school students in Taiwan." Bulletin of Educational Research 52.4 (2006): 35-70.

[28] Chiang, Fang-Shen. "An examination on the effects of cramming among junior high school students." 
Journal of Taipei Municipal University of Education 37.1 (2006): 131-148.

[29] Kwo, Ora, and Mark Bray. "Understanding the nexus between mainstream schooling and private supplementary tutoring: Patterns and voices of Hong Kong secondary students." Asia Pacific journal of education 34.4 (2014): 403-416. 